\title{
Monitoring Suspended Solids and Total Phosphorus in Finnish Rivers
}

\author{
Mauno Rönkkö and Okko Kauhanen ${ }^{1}$ Jari Koskiaho, Niina Kotamäki and Teemu Näykki ${ }^{2}$ \\ Markku Ohenoja and Esko Juuso ${ }^{3}$ Maija Ojanen, Petri Koponen and Ville Kotovirta ${ }^{4}$ \\ ${ }^{1}$ Department of Environmental Science, University of Eastern Finland, Kuopio, Finland, \\ \{mauno.ronkko, okko.kauhanen\} @uef.fi, \\ ${ }^{2}$ Finnish Environment Institute,Helsinki, Finland, \\ \{jari.koskiaho, niina.kotamaki, teemu.naykki\}@ymparisto.fi \\ ${ }^{3}$ Control Engineering, Faculty of Technology, University of Oulu, Finland, \\ \{markku.ohenoja, esko. juuso\} @oulu.fi \\ ${ }^{4}$ VTT Technical research Centre of Finland, VTT, Finland, \\ \{maija.ojanen, petri.koponen, ville.kotovirta\}@vtt.fi
}

\begin{abstract}
Monitoring of water quality should not be solely based on laboratory samples. Such activity, although producing reliable results, cannot provide an accurate enough temporal coverage for water quality monitoring. The Finnish Environment Institute, SYKE, has therefore established numerous online water monitoring stations that continuously monitor water quality. The problem with the automatic monitoring, however, is that the recorded values are not reliable as such and need to be subject to quality control and uncertainty estimation. Here, as the main contribution, we present a computational service that we have implemented to automate and integrate the water quality monitoring process. We also present a case study regarding the river Väänteenjoki and discuss the obtained uncertainty results and their implication.
\end{abstract}

Keywords: environmental measurements, quality control, uncertainty estimation, computational service, river

\section{Introduction}

The Finnish environmental authorities have regularly monitored water quality variables such as total suspended solids (TSS) and total phosphorus (TP) concentrations in major Finnish rivers since 1960s. The aim is to get general idea on the amounts of substances transported into the Finnish lakes and coastal areas and to detect possible trends. Presently, water quality and flow are monitored at 29 downstream monitoring stations of Finland's major rivers discharging into the Baltic Sea. There are also numerous inland river monitoring sites included, for instance, in the Finnish Eurowaternet (Niemi and Raateland, 2007). Annually, 13 to 22 water samples are taken and analyzed for TSS and TP (The Finnish Ministry of Environment, 2014) in addition to other substances.

SYKE has published quality recommendations for laboratories producing and delivering environmental monitoring data for registers of water quality in Finland
Table 1. Recommended LOQ and MU (k=2) values for the measurement of TSS, TP and turbidity in monitoring of natural waters in Finland (Näykki et al., 2013).

\begin{tabular}{lllll}
\hline Parameter & Unit & LOQ & Range & MU \\
\hline TSS & $\mathrm{mg} / \mathrm{l}$ & 2 & $2-3$ & \pm 0.5 \\
& & & $>3$ & $\pm 20 \%$ \\
TP & $\mu \mathrm{g} / \mathrm{l}$ & 3 & $3-10$ & \pm 1.5 \\
& & & $>10$ & $\pm 15 \%$ \\
Turbidity & NTU & 0.5 & $0.5-1$ & \pm 0.2 \\
& (or FNU) & & & \\
& & & $>1$ & $20 \%$ \\
\hline
\end{tabular}

(Näykki et al., 2013). Examples of the recommended limits of quantification (LOQ) and expanded measurement uncertainties (MU) are given in Table 1. The challenge in automating water quality monitoring is that the measurement data have not only significant seasonal variation but also erroneous values. Thus, without proper quality control and reliable uncertainty estimation, the data has little value. Thus far, this activity has been performed manually by environmental researchers.

As a solution, we have implemented a computation service based on an Enterprise Service Bus Architecture. The service provides means for online quality control and integration of uncertainty estimation. It automates the sequence of operations performed earlier by the researchers; thus, providing more reliable results in a scalable and extensible manner. The service also enables reliable monitoring of the changes in water quality and flow over shorter periods of time.

\section{Materials and Methods}

The river Väänteenjoki was used here as the measurement site. A turbidity sensor was assembled at the Väänteenjoki site in the Karjaanjoki River Basin $\left(2046 \mathrm{~km}^{2}\right)$ in southern Finland, shown in Figure 1, as a part of the sensor network 


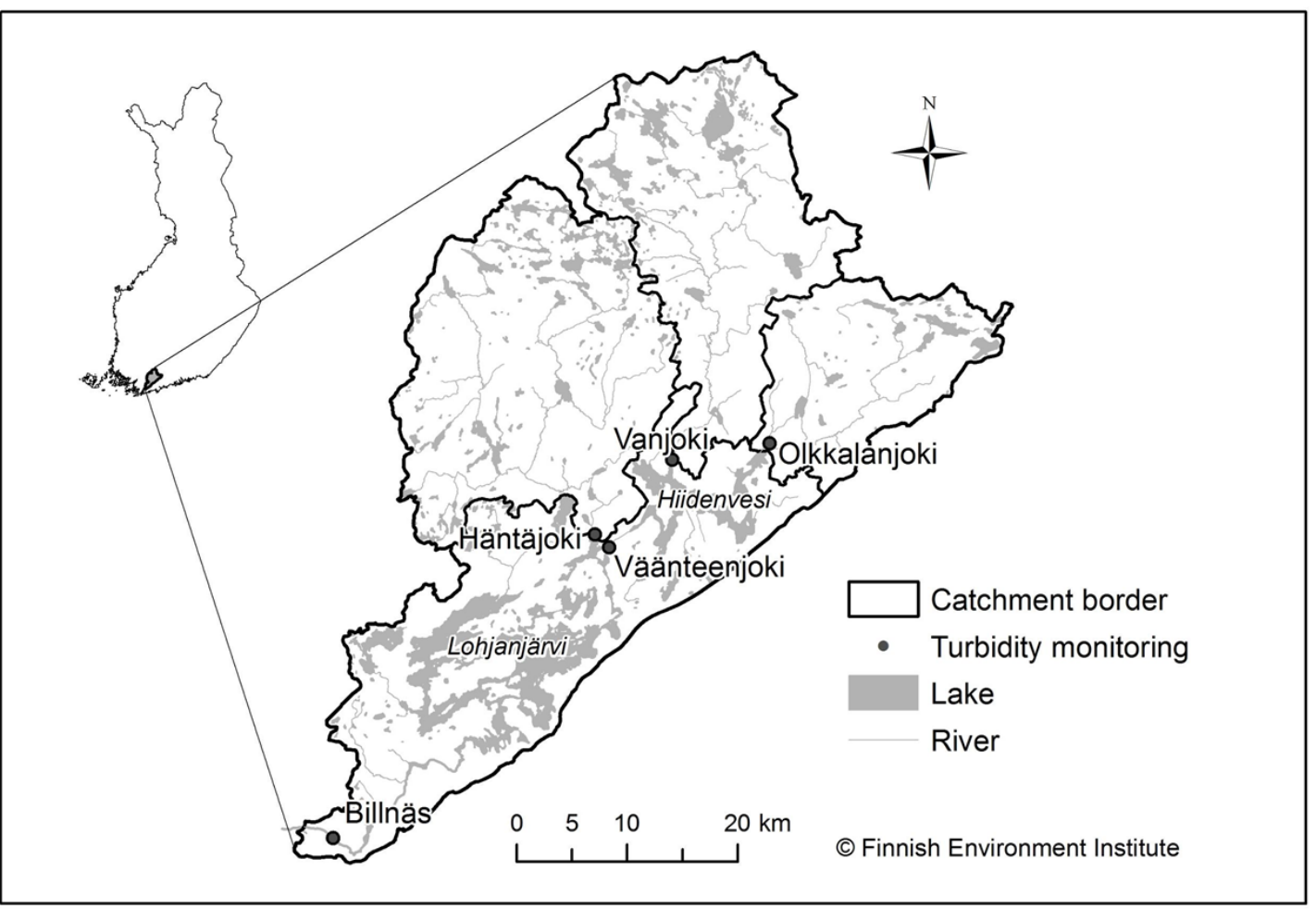

Figure 1. Location of the Väänteenjoki measurement site in the middle of the Karjaanjoki river basin.

established during the years 2007 and 2008 in the SoilWeather project (Kotamäki et al., 2009). The river basin is mainly covered by forest (60\%), the rest of the area being agricultural land (13\%), lakes and rivers (12\%), and population centers $(9 \%)$. The Väänteenjoki measurement site is located between the two major lakes of the Karjaanjoki basin. From the lake Hiidenvesi (area $29 \mathrm{~km} 2$, mean depth $6.7 \mathrm{~m}$ ), waters flow via the river Väänteenjoki into the lake Lohjanjärvi (area $92 \mathrm{~km} 2$, mean depth $12.7 \mathrm{~m}$ ).

The monitoring process of the Väänteenjoki site is depicted in Figure 2. In the Väänteenjoki case, an OBS3+ sensor by Campbell Scientific was used. It emits a nearinfrared light into the water, measures the light that scatters back from the suspended particles, and transforms this information into turbidity values (in Nephelometric Turbidity Units, NTU). The sensor collects and transmits the data to a server as SMS messages. The received messages are decoded as measurements with timestamps. The measurements are stored into a HydroTempo database maintained by SYKE.

Laboratory samples are collected once in a month. More frequent sampling can also be carried out during the high water runoff seasons. Laboratory turbidity measurement is carried out according to the international standard ISO 7027 (International Organization for Standardization, 1999). Turbidity is measured nephelometrically; the instrument measures the scattered light using the detector angle of 90 degrees from incident light. Instrument is calibrated with formazine standard solutions, and the turbidity of the tested water sample is expressed in Formazine Nephelometric Units (FNU). Note that FNU equal to NTU. TSS are determined at laboratory according to the standard EN 872 (European Committee for Standardization, 2005a), where water samples are filtered with GF/C glass fibre filter and dried at $105{ }^{\circ} \mathrm{C}$. The mass of the residue retained on the filter is determined by weighing. Measurement of TP is based on standard EN ISO 156812 (European Committee for Standardization, 2005b) and recommendations of the analyzer manufacturer. Phosphorus is converted to orthophosphate by an acid-persulfate digestion prior measurement, where orthophosphate reacts in an acid solution containing molybdate and antimony forming an antimony phosphomolybdate complex. Reduction of the complex with ascorbic acid forms a strongly coloured molybdenium blue complex which is measured at the wavelength of $880 \mathrm{~nm}$.

In a previous study (Koskiaho et al., 2015), turbidity recorded by an OBS3+ sensor at the Väänteenjoki site was calibrated against the turbidity determined from water samples taken near the sensor. Calibration equation, shown in Table 2, was determined according to linear regression between the values of the water samples and the simultaneous values recorded by the sensor. Because turbidity does not denote the content of substance in water, it cannot be directly used in calculations of material fluxes. Thus, correlations of turbidity with the concentrations of 


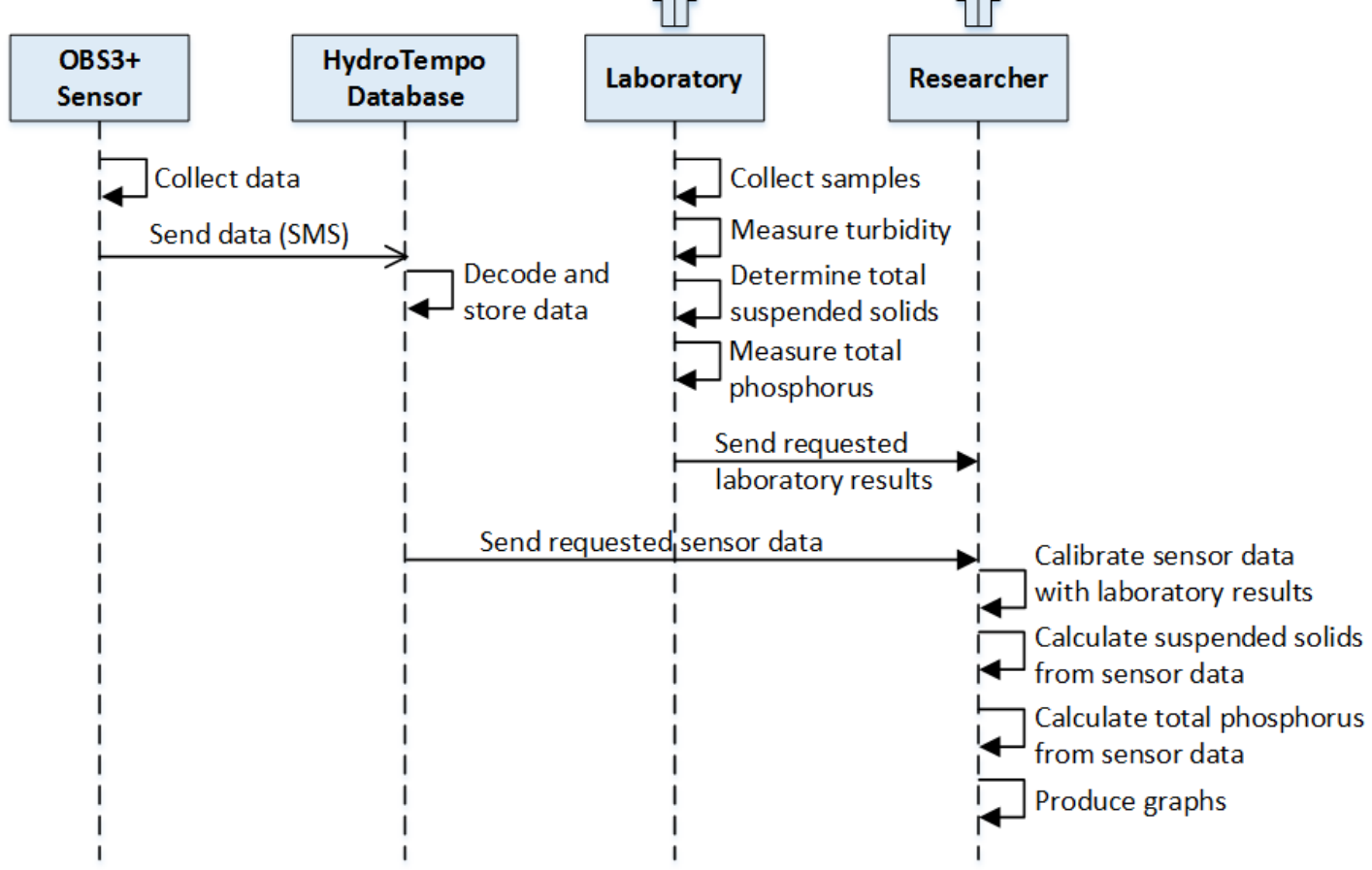

Figure 2. The monitoring process of the Väänteenjoki site.

TSS and TP were determined from the 2009-2012 water sample data collected at Väänteenjoki to convert the sensor-based, calibrated turbidity data to hourly concentrations of TSS and TP. The conversion equations based are presented in Table 2.

It should be noted that there may be events where turbidity jumps into the maximum (e.g. 250 NTU) and stays there for some hours. In some cases such events have lasted a day or two. The events could be caused by a storm followed by rapidly increasing water flow. In a previous study (Koskiaho et al., 2015), these events were manually checked, removed, and replaced with interpolated values before further processing. In (Koskiaho et al., 2015), however, measurement uncertainty was not estimated.

We have implemented a computational service that automates and integrates uncertainty estimation to the sequence of operations depicted earlier in Figure 2. The service architecture, shown in Figure 3, uses an Enterprise Service Bus (ESB) to connect different subsystems and to relay data between the subsystems. When the researcher inquires TSS for a specific river, ESB is used to acquire relevant measurement data and laboratory results. That data is passed to an online computational subservice. It computes TSS and TP for the river based on turbidity measurements. It also computes (combined) measurement uncertainty for the result.

In the computation, the calibration equation and related conversion equations are used as discussed earlier in Table 2. The computation results obtained by using these linear regression equations are then subjected to uncertainty estimation as discussed in (Ellison and Williams, 2012; Bar-

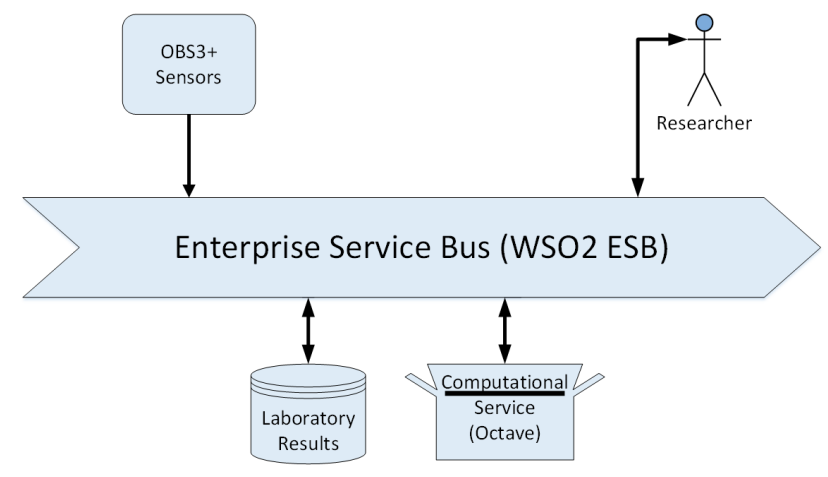

Figure 3. ESB based architecture implementing the service for computing TSS and TP along with measurement uncertainty estimation.

wick, 2003). The results regarding the amount of TSS, including the linear regression equations, are then delivered to the researcher along with the (total) measurement uncertainty. The measurement uncertainty is a reliability estimate and can be used to compare the measurement results among each other or with reference values (JCGM, 2008).

The combined measurement uncertainty includes contribution from the laboratory reference measurement and the performance of the measurement models, i.e. how well the measured values fit in the model, and how repeatable the online measurements are. The laboratory reference uncertainty is estimated according to the Nordtest approach (Magnusson et al., 2012) and ISO standard 11352 (International Organization for Standardization, 1012), where 
Table 2. Calibration equations and coefficients of determination $\left(r^{2}\right)$ derived from the relation between the sensor recordings and water samples, and equations to convert the calibrated turbidity to TSS and TP concentrations.

\begin{tabular}{lll}
\hline Calibration equation & \multicolumn{2}{c}{ Conversion equation for the concentration of } \\
& TSS $[\mathrm{mg} / \mathrm{l}]$ & TP $[\mu \mathrm{g} / \mathrm{l}]$ \\
\hline $\mathrm{y}=2.8+2.12 \mathrm{x} ; \mathrm{r}^{2}=0.86$ & $\mathrm{z}=1.6+0.78 \mathrm{y} ; \mathrm{r}^{2}=0.74$ & $\mathrm{z}=14.3+1.76 \mathrm{y} ; \mathrm{r}^{2}=0.82$ \\
\hline where $\mathrm{x}$ & $=$ recorded turbidity (NTU, raw data) \\
$y$ & $=$ calibrated turbidity (NTU, final data for further calculations) \\
$z$ & $=$ TSS or TP concentration determined from clibrated turbidity
\end{tabular}

Table 3. Uncertainty budget for the turbidity, TP and TSS concentration measurements.

\begin{tabular}{llll}
\hline & $\begin{array}{l}\text { Turbidity } \\
\text { (25 FNU) }\end{array}$ & $\begin{array}{l}\text { TP } \\
(\mathbf{6 0} \mu \mathbf{g} / \mathbf{l})\end{array}$ & $\begin{array}{l}\text { TSS } \\
\mathbf{( 2 0} \mathbf{~ m g} / \mathbf{l})\end{array}$ \\
\hline $\begin{array}{l}\text { Laboratory analysis } \\
\begin{array}{l}\text { Turbidity sensor } \\
\text { measurement model }\end{array}\end{array}$ & $7.8 \%$ & $7.5 \%$ & $7.5 \%$ \\
$\begin{array}{l}\text { Phosphorus/solids } \\
\text { measurement model }\end{array}$ & $7.8 \%$ & $7.8 \%$ \\
$\begin{array}{l}\text { Combined standard } \\
\text { uncertainty }\end{array}$ & $12.8 \%$ & $16.4 \%$ & $17.4 \%$ \\
$\begin{array}{l}\text { Expanded uncertainty } \\
(k=2)\end{array}$ & $25.6 \%$ & $32.9 \%$ & $38.0 \%$ \\
\hline
\end{tabular}

combined standard uncertainty consists of two main components: the within-laboratory reproducibility and the uncertainty due to possible bias. The quality recommendation for reporting measurement results and uncertainties does not include the uncertainty due to sampling (Näykki et al., 2013). The uncertainty of the linear regression measurement models, $u_{c_{0}}$, is estimated with help of (Ellison and Williams, 2012):

$$
u_{c_{0}}=\frac{S}{B_{1}} \sqrt{\frac{1}{p}+\frac{1}{n}+\frac{\left(c_{0}-\bar{c}\right)^{2}}{S_{x x}}}
$$

where $S$ is the residual standard deviation of the measurement model, $B_{1}$ is the slope of the measurement model, $p$ is the number of replicate measurements in the determination of the concentration $c_{0}, n$ is the number of replicate measurements in the determination of the mean calibration value $\bar{c}$, and $S_{x x}$ is the standard deviation of the measured values and the mean calibration value. The uncertainty related to the repeatability of the measurements is included in Equation (1).

\section{Results and Discussion}

Hourly time series of the calibrated turbidity measured by sensors (curves) together with turbidity analyzed from water samples (dots) are presented in Figure 4. As suggested by the equality of sampled and sensor-based values, calibration of the sensors was successful.

The turbidity curve of the river Väänteenjoki, also shown in Figure 4, differed strongly from those of the other measurement sites dealt with in (Koskiaho et al., 2015), which showed clearly sharper general form and higher peak values. The difference was claimed to be a consequence of the retention effect of the lake Hiidenvesi and the close proximity of the Väänteenjoki measurement site to the lake. In other measurement sites, the distance to the upstream lakes was much longer, or the lakes were small.

The uncertainty components are listed in Table 3 . In this example, a typical value for the turbidity is $25 \mathrm{FNU}$, for the TP is $60 \mu \mathrm{g} / \mathrm{l}$, and for TSS is $20 \mathrm{mg} / \mathrm{l}$. The standard uncertainty $(\mathrm{k}=1)$ of the laboratory analysis is $10 \%$ for the turbidity in the range $>1 \mathrm{FNU}$, and $7.5 \%$ for the TP and TSS in the ranges of $>10 \mu \mathrm{g} / \mathrm{l}$ and $>3 \mathrm{mg} / \mathrm{l}$, respectively. Using Equation (1), we obtain the standard uncertainty estimates for the turbidity sensor calibration, $7.8 \%$, and for the TP and TSS measurement models, $7.7 \%$ and $12 \%$, respectively. The TP and TSS contents are determined based on turbidity, so the calibration of the turbidity sensor must be included. The combined standard uncertainty is calculated as a square sum of the individual, uncorrelated components (JCGM, 2008). Figure 5 demonstrates the expanded uncertainty (in content) as a function of measured turbidity, TP and TSS. The measured values presented are between the minimum and maximum values of the data set of our example.

It can be seen that all the uncertainty components, laboratory analysis and the measurement models, are of the order of the same magnitude. The linear regression models are based on the whole dataset 2009 - 2012. In this case, there is no significant difference in terms of uncertainty whether the model is fitted based on the whole dataset or on yearly basis.

Using the presented measurement models practically doubles the measurement uncertainty as compared with the laboratory analysis, but on the other hand the online monitoring provides more representative and frequent information in the water quality. In Figure 6, this is illustrated by presenting the relative standard error of the mean for TP in different variation levels, calculated based on the two different monitoring processes and their measurement uncertainties presented in Table 3 .

The more frequent data of online monitoring (24 samples per day) enables following the trends in daily basis with low estimation error, whereas infrequent laboratory 


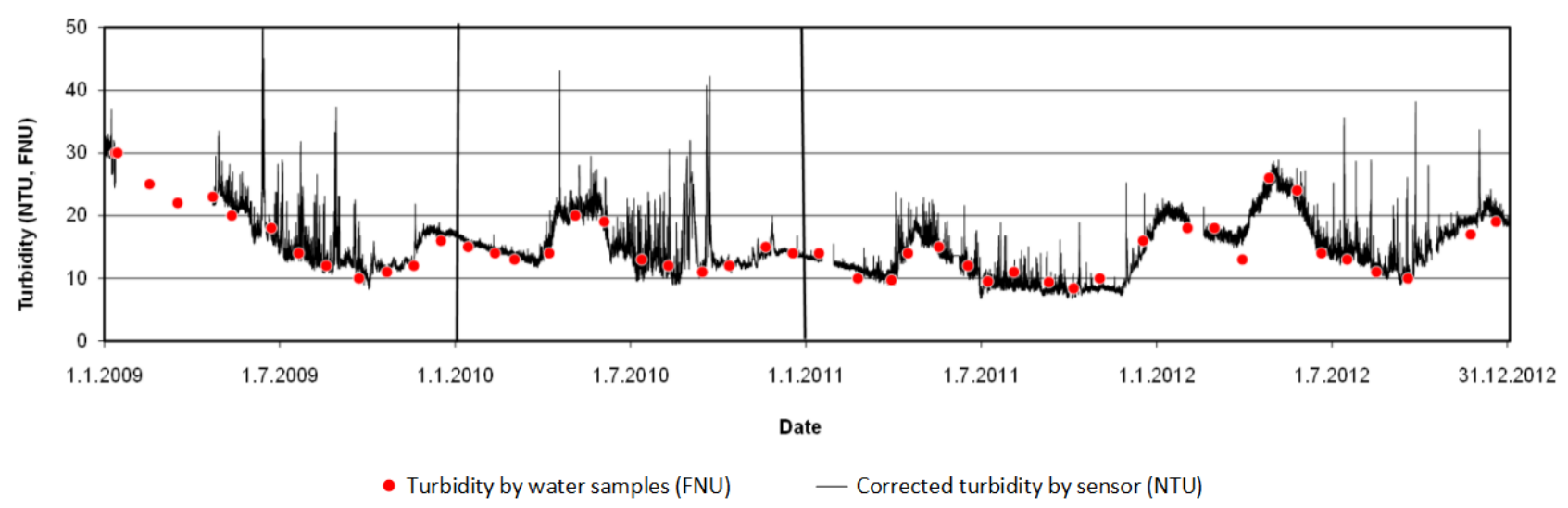

Figure 4. Hourly time series of the corrected turbidity measured by sensors (NTU) together with turbidity analyzed from water samples (FNU) in Väänteenjoki measurement site.

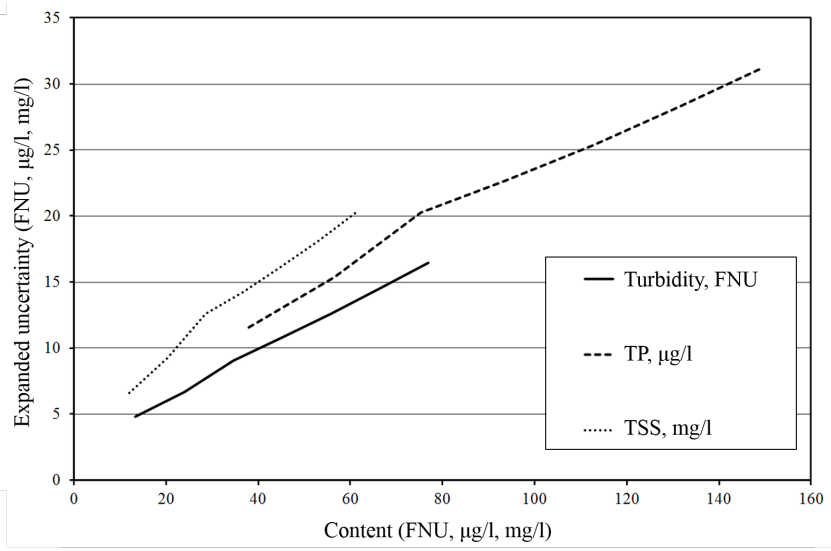

Figure 5. Expanded uncertainties of turbidity (FNU, solid line), $\mathrm{TP}(\mu \mathrm{g} / \mathrm{l}$, dashed line) and TSS (mg/l, dotted line) as a function of content.

measurements ( 1 sample per month) is only suitable for estimating yearly averages with a comparable estimation error.

As compared with the quality recommendations in $\mathrm{Ta}-$ ble 1 , the uncertainty of the laboratory analysis is equal to the recommendation for turbidity and TP. For TSS, the quality recommendation is $20 \%$, and in this case $15 \%$.

For the measurement models, the total number of measurement data points is 45 for turbidity and 46 for TP and TSS. The coefficients of determination for the measurement model equations are $0.86,0.82$ and 0.74 for the turbidity, TP and TSS measurement models, respectively. The coefficient of determination of 0.90 would result in uncertainties of $6.5 \%, 6.0 \%$ and $7.7 \%$ for turbidity, TP, and TSS, respectively. With the present laboratory analysis uncertainties, these uncertainties would produce respective expanded uncertainties of $24 \%, 31 \%$ and $32 \%$. If the coefficient of determination is 0.95 , the turbidity sensor measurement model would result in $4.5 \%$ standard uncertainty. This would result in $22 \%$ expanded uncertainty in turbidity, $29 \%$ in TP, and $31 \%$ in TSS measurement model.
However, the coefficient of determination of 0.90 would be obtainable by using an outlier detection algorithm. This would require removal of two most deviating points from turbidity model, five from TP model and ten points from the TSS model. Even the coefficient of determination of 0.95 is obtainable, at least with turbidity measurement model. This would require removing 11 most deviating measurement points from the model. Reducing the size of the data set down to 34 points does not increase the uncertainty of the model significantly.

\section{Conclusions}

A computational service for monitoring TSS and TP was introduced in this study. The service also integrates measurement uncertainty estimation and delivers monitoring results with uncertainty information. The service was implemented by using a scalable and extensible architecture based on the use of an Enterprise Service Bus.

The monitoring results obtained for the river Väänteenjoki were presented and discussed. The results indicate that online monitoring does not fully fit within the recommended limits of quantification. The advantage of online monitoring, however, is that it is a continuous activity and it supports monitoring of quick events and changes in trends. This is something that would not be feasible by using laboratory sampling only. Thus, in together with laboratory sampling online monitoring provides a more accurate situation picture of the state and quality of Finnish rivers.

\section{Acknowledgements.}

We thank the Finnish Funding Agency for Technology and Innovation (TEKES) for funding this research. This work has been carried out in TEKES funded CLEEN SHOK programme "Measurement, Monitoring and Environmental Assessment". 


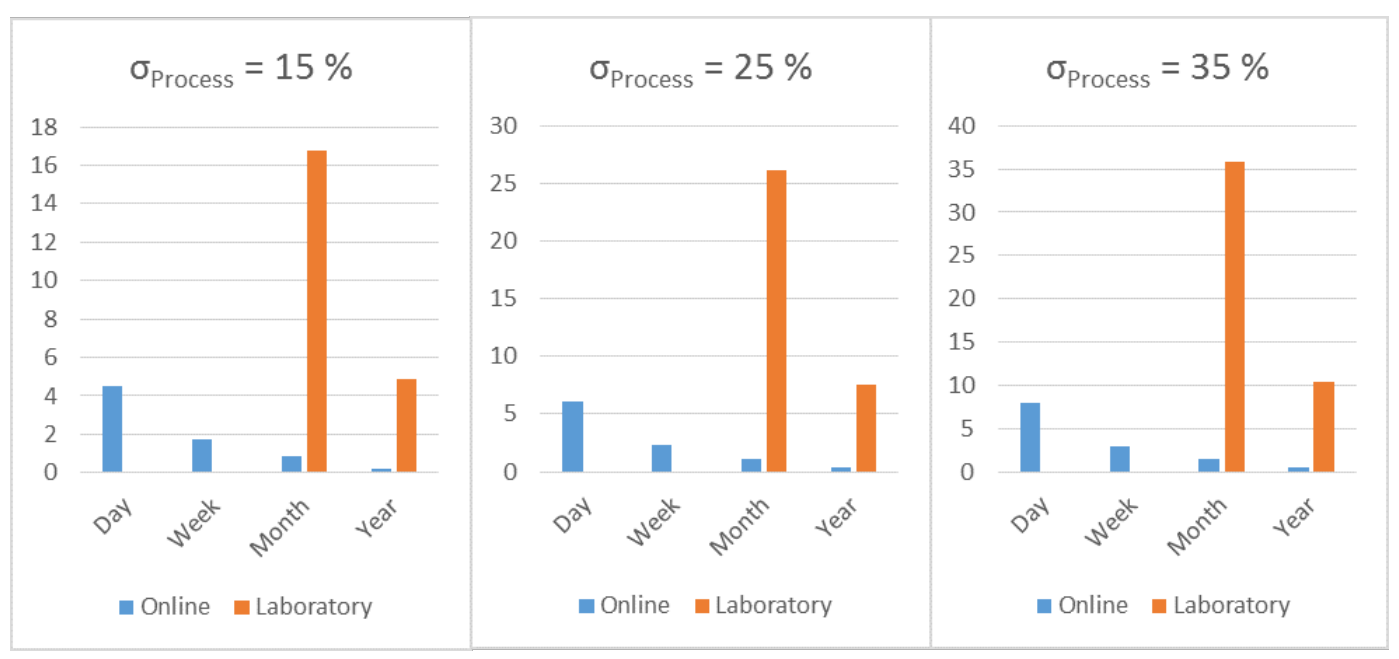

Figure 6. Relative standard error of the mean (SE) with the different monitoring processes and different observation periods calculated as $(\%)=100 \sqrt{\left(\sigma_{p}^{2}+\sigma_{M}^{2}\right) / n}$.

\section{References}

V. Barwick. Preparation of calibration curves: A guide to best practice, 2003.

S. L. R. Ellison and A. Williams. Eurachem/citac guide quantifying uncertainty in analytical measurement, third edition, 2012.

European Committee for Standardization. EN 872. water quality - determination of suspended solids, 2005a.

European Committee for Standardization. EN ISO 15681-2. water quality - determination of orthophosphate and total phosphorus contents by flow analysis (FIA and CFA). part 2: Method by continuous flow analysis (CFA), 2005b.

International Organization for Standardization. ISO 11352:2012, water quality. estimation of measurement uncertainty based on validation and quality control data, 1012 .

International Organization for Standardization. ISO 7027. water quality - determination of turbidity, 1999.

JCGM. Evaluation of measurement data - guide to the expression of uncertainty in measurement (jcgm 100:2008, gum 1995 with minor corrections), 2008.

J. Koskiaho, S. Tattari, and E. Röman. Suspended solids and total phosphorus loads and their spatial differences in a lakerich river basin as determined by automatic monitoring network. Environmental monitoring and assessment, 187(4):1$12,2015$.

N. Kotamäki, S. Thessler, J. Koskiaho, A. O. Hannukkala, H. Huitu, T. Huttula, J. Havento, and M. Järvenpää. Wireless in-situ sensor network for agriculture and water monitoring on a river basin scale in Southern Finland: Evaluation from a data user's perspective. Sensors, 9(4):2862-2883, 2009.

B. Magnusson, T. Näykki, H. Hovind, and M. Krysell. Nordtest technical report 537: Handbook for the calculation of measurement uncertainty in environmental laboratories, 3.1 edn., 2012.
T. Näykki, H. Kyröläinen, A. Witick, I. Mäkinen, R. Pehkonen, T. Väisänen, P. Sainio, and M. Luotola. Quality recommendations for data entered into the environmental administration's water quality registers: Quantification limits, measurement uncertainties, storage times and methods associated with analytes determined from waters (in Fnnish), environmental administration guidelines 4/2013, 2013. URL https: / / helda.helsinki.fi/handle/10138/40920.

J. Niemi and A. Raateland. River water quality in the Finnish eurowaternet. Boreal Environment Research, 12:571-584, 2007.

The Finnish Ministry of Environment. Suomen merenhoidon seurantakäsikirja (marine management monitoring handbook of Finland), 2014. URL

WwW. ymparisto.fi/download/noname/\$ \$7BD36B07E3-30F7-4F48-8B55-D809AC74FA8B\$응 \$D/98219. 